Portland State University

PDXScholar

\title{
The Role of Ethics Online and Among Social Media Designers
}

Meredith James

Portland State University, mejames@pdx.edu

Follow this and additional works at: https://pdxscholar.library.pdx.edu/artdesign_fac

Part of the Communication Technology and New Media Commons, Critical and Cultural Studies Commons, and the Ethics and Political Philosophy Commons Let us know how access to this document benefits you.

\section{Citation Details}

James, Meredith, "The Role of Ethics Online and Among Social Media Designers" (2017). School of Art + Design Faculty Publications and Presentations. 6.

https://pdxscholar.library.pdx.edu/artdesign_fac/6

This Presentation is brought to you for free and open access. It has been accepted for inclusion in School of Art + Design Faculty Publications and Presentations by an authorized administrator of PDXScholar. Please contact us if we can make this document more accessible: pdxscholar@pdx.edu. 


\title{
the role of ethics online and among social media designers
}

\author{
meredith james
}

PORTLAND STATE UNIVERSITY 


\section{[a set of examples and the questions they pose]}

I've been developing this scholarship for a while, but some of what I'm about to reference has hit a head with the election. 


\section{a few examples from facebook}




\section{1 blue feed, red feed}




\section{SCENARIO}

The Wall Street Journal has created a page that dynamically loads content from Facebook feeds that compare left-liberal feeds with right-conservative feeds. 
○ 0 (1) (BBP $^{2} \equiv \quad$ graphics.wsj.com

C

๑ 吕 +

See Liberal Facebook and Conservative Facebook, Side by Side

By Jon Keegan

Published May 18, 2016 at 8:00 a.m. ET | Updated hourly

FILTER FEEDS BY TOPIC:

\begin{tabular}{ll|l|l|l|l|l|l|l}
\hline PRESIDENT TRUMP & AFFORDABLE CARE ACT & GUNS & ABORTION & ISIS & EXECUTIVE ORDER IMMIGRATION & PROTESTS
\end{tabular}

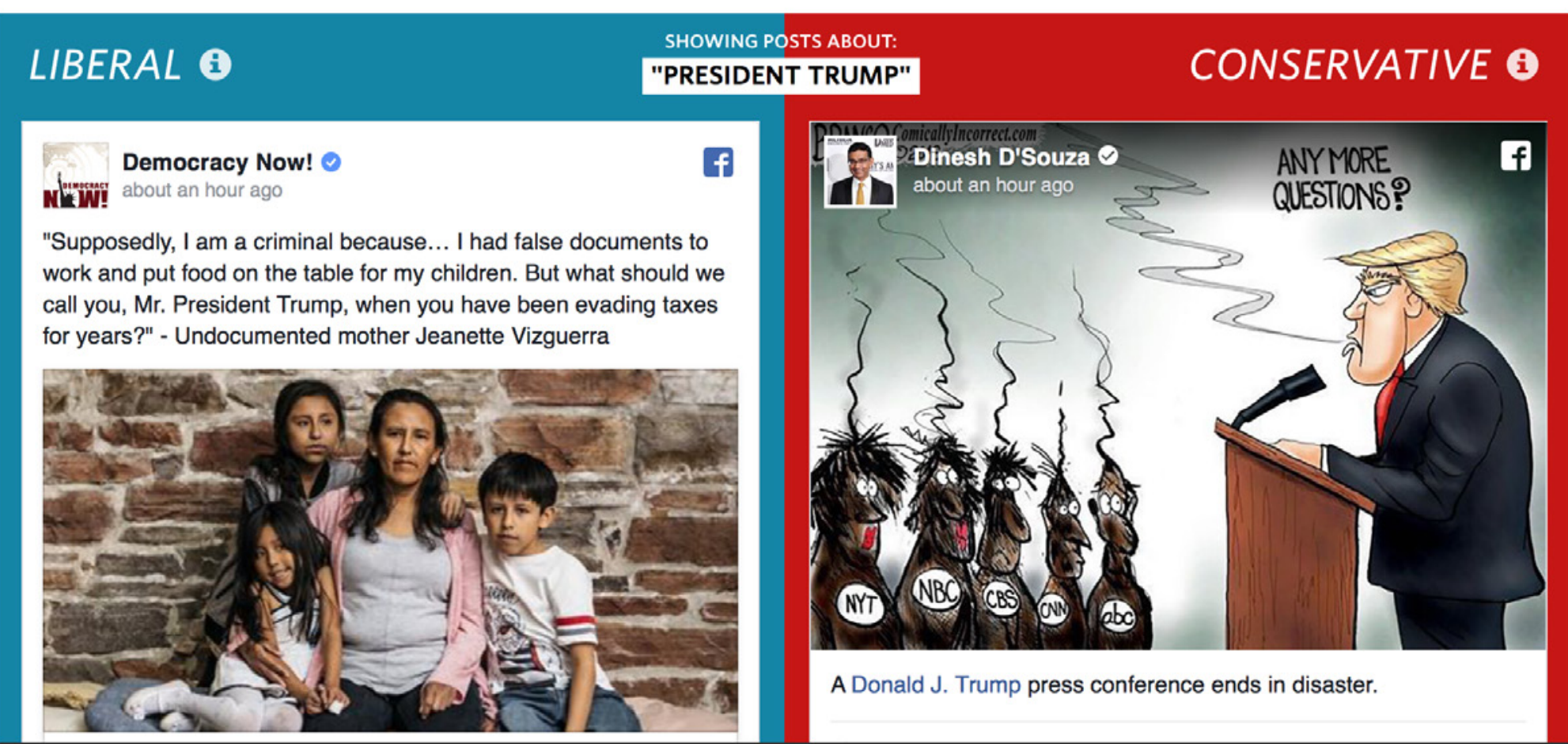

These Facebook posts do not represent the reporting or opinion of The Wall Street Journal, and are not verified, edited or endorsed in any way. Read our

$\wedge$ Note the disclaimer 


\section{2.ls vs ferguson}


“In August 2014, I watched it all online as Facebook's news feed algorithm flooded my timeline with the Ice Bucket Challenge, a worthwhile charity drive for ALS research, while also algorithmically hiding updates from the growing Ferguson protests. Many of my friends were furiously posting about Ferguson on Facebook and on Twitter, but I only saw it on Twitter. Without Twitter to get around it, Facebook's news feed might have algorithmically buried the beginning of what has become a nationwide movement focusing on race, poverty and policing." 


\section{Facebook Said Its Algorithms Do Help Form Echo Chambers, and the Tech Press Missed It}

ZEY NEP TUFEKCI is an assistant professor in the School of Information and Library Science at the University of North Carolina, a faculty associate at the Berkman Center for Internet and Society at Harvard University and a former fellow at the Center for Internet Technology Policy at Princeton University. Her forthcoming book from Yale University Press is tentatively titled Beautiful Tear Gas: The Ecstatic, Fragile Politics of Networked Protest in the 2I st Century.

Last week, researchers who work for Facebook released a study titled "Exposure to ideologically diverse news and opinion on Facebook." It was about a crucial topic: Does the increasing role of algorithms of personalization and "engagement" on online platforms end up filtering out viewpoints that are different than our own?

The study, published in Science, generated a flurry of media coverage with headlines such as "Facebook Echo Chamber Isn't Facebook's Fault, Says Facebook” (Wired), “Facebook says its algorithms aren't responsible for your

(Tufekci is criticizing a study published in Science, that used an arguably shoddy methodology obscuring serious underlying issues with Facebook) 


\section{$\mathbf{3}$ racism and hate}




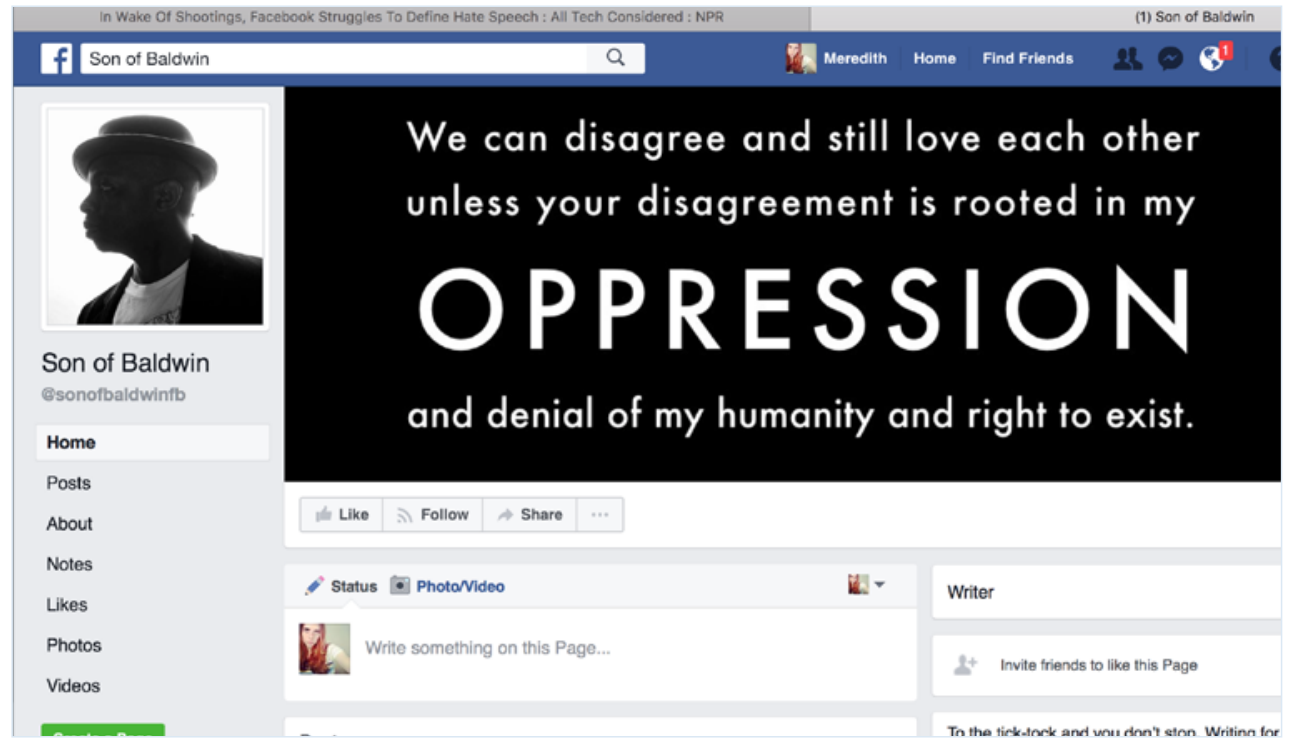

Statements on racial equality: taken down
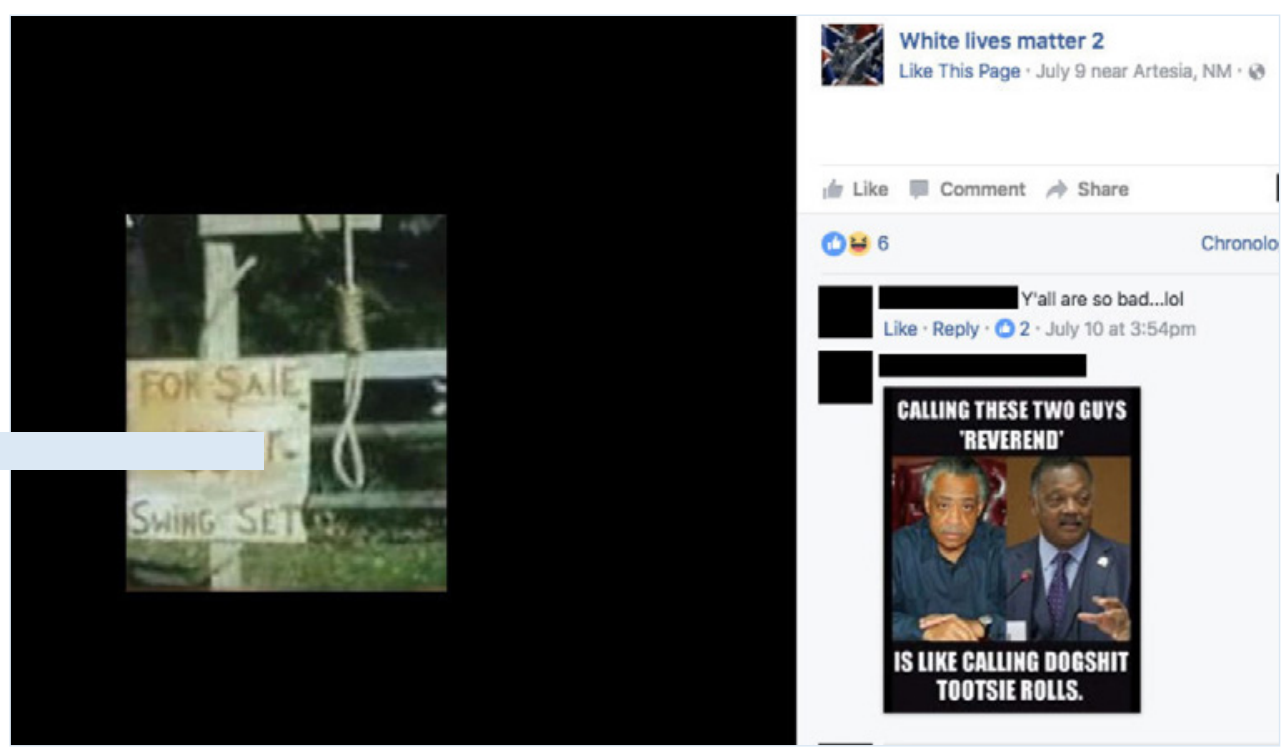

Lynching image referenced below, (I have crossed out a slur with the blue line)

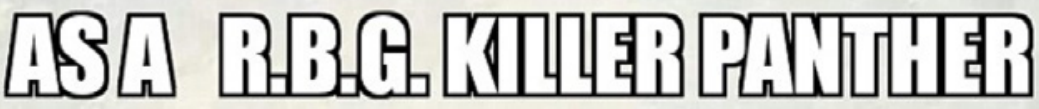

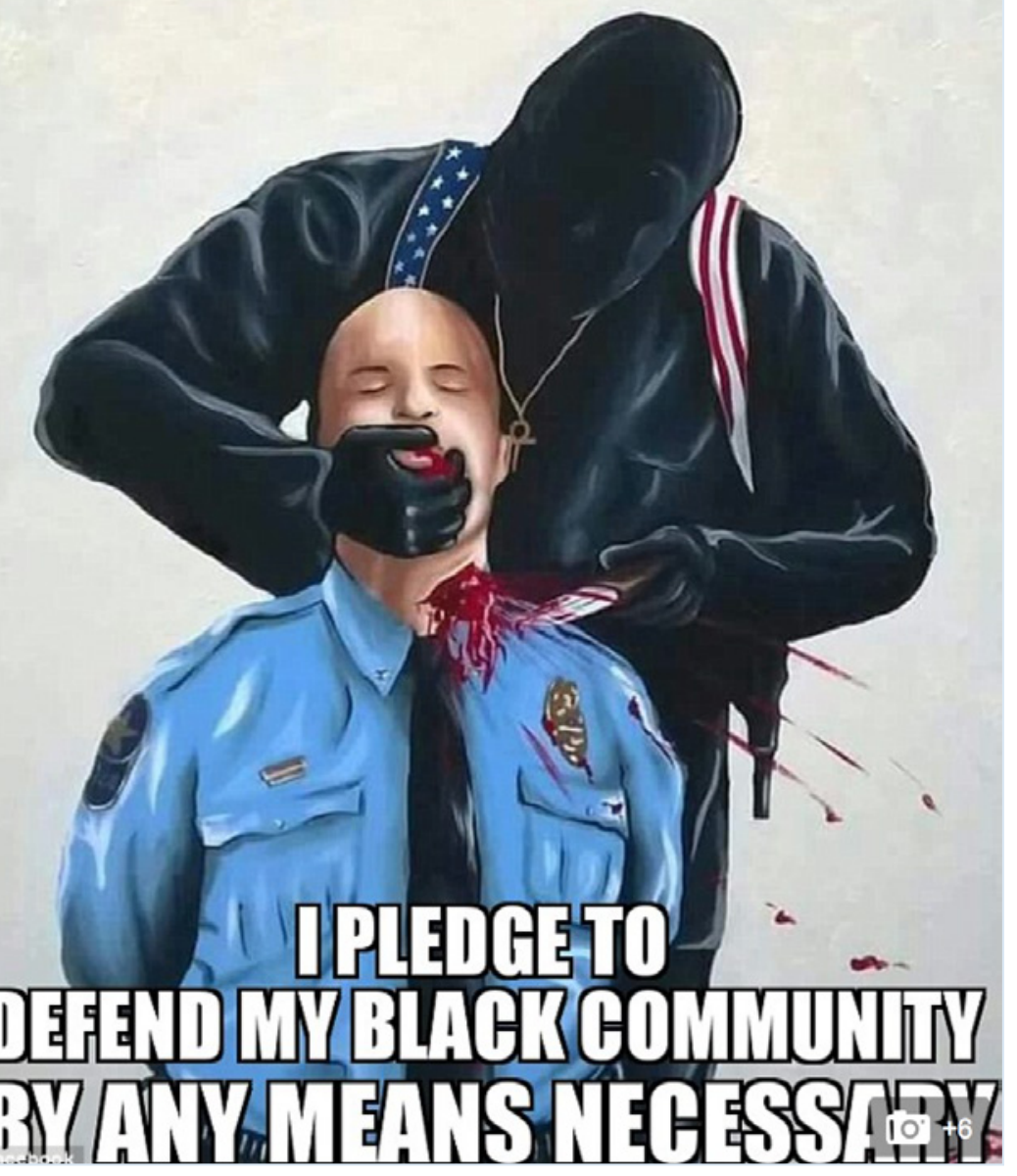

Meme calling for killing cops: kept up

For a great discussion on race and power dynamics online, see Poor Meme, Rich Meme 
"'It's a reference to lynching-and making a joke of lynching...' this is 'obviously a pretty difficult picture to look at' and...unless there's a deeper context, 'I would say it has no place on here.' Facebook left it up [the image], and stands by that decision."'

Facebook's stance on any particular image, post or meme, is chronically inconsistent. Flagged content is manually approved at Facebook, and when posts get flagged, they get an average of 10 seconds of review by a person (who is paid by the number of posts they moderate). Facebook on the whole seems to be overwhelmed, but more so, also defers to the public for direction on ethical decisions. 
There are many, many other examples of the overall attitude, privilege and racial dynamic that permeates online culture. 
"Facebook is on a kick to declare that the news feed algorithm it creates, controls and changes all the time is some sort of independent force of nature or something that is merely responsive to you, without any other value embedded in its design. But in reality, the algorithm is a crucial part of Facebook's business model."

“We started out of a college dorm. I mean, c'mon, we're Facebook. We never wanted to deal with this shit." 


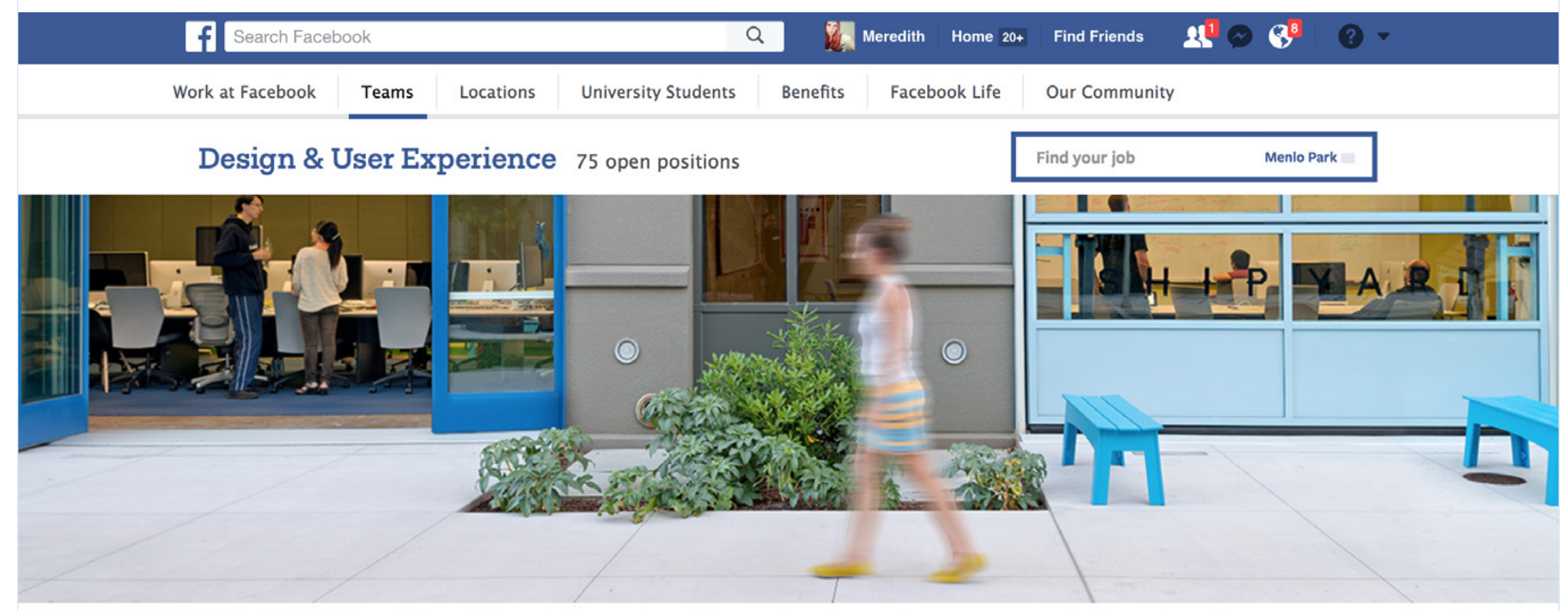

We value great design and prioritize it across every single thing we build at Facebook. From the internationally recognized LIKE button to our mobile platform, all of our products feature simple, human centered designs. We conduct research and rigorously test each design to ensure we launch beautiful products with a seamless user experience.

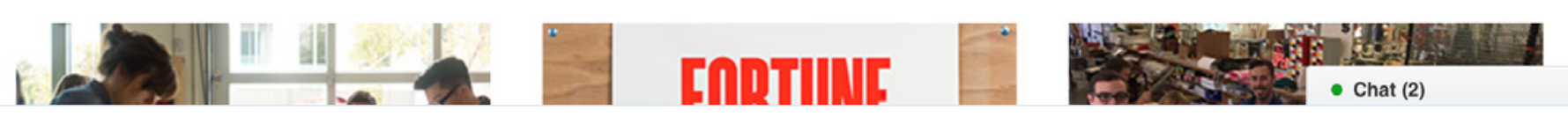

A reality check on how many designers are employed or courted at companies like Facebook, Google, Twitter, Instagram, etc. 


\section{ETHICAL QUESTIONS}

Who is in charge of allowing or promoting specific content; who is the authority; how are these decisions being made, and what are the consequences 
"A former employee...says there is a cultural problem, a stubborn blindness at Facebook and other leading Internet companies like Twitter. The source says: "The hardest problems these companies face aren't technological. They are ethical, and there's not as much rigor in how it's done." 


\section{4 google search results}




\section{SCENARIO}

\section{Recently, Google got in trouble for skewed search results on the holocaust, and issues of race and gender.}


Observations I've made via general use were confirmed for me by a Google employee in 2015. Google skews search results based on paid rankings, location, specific criteria, and whether you're logged in or not. My students have had similar experiences. 


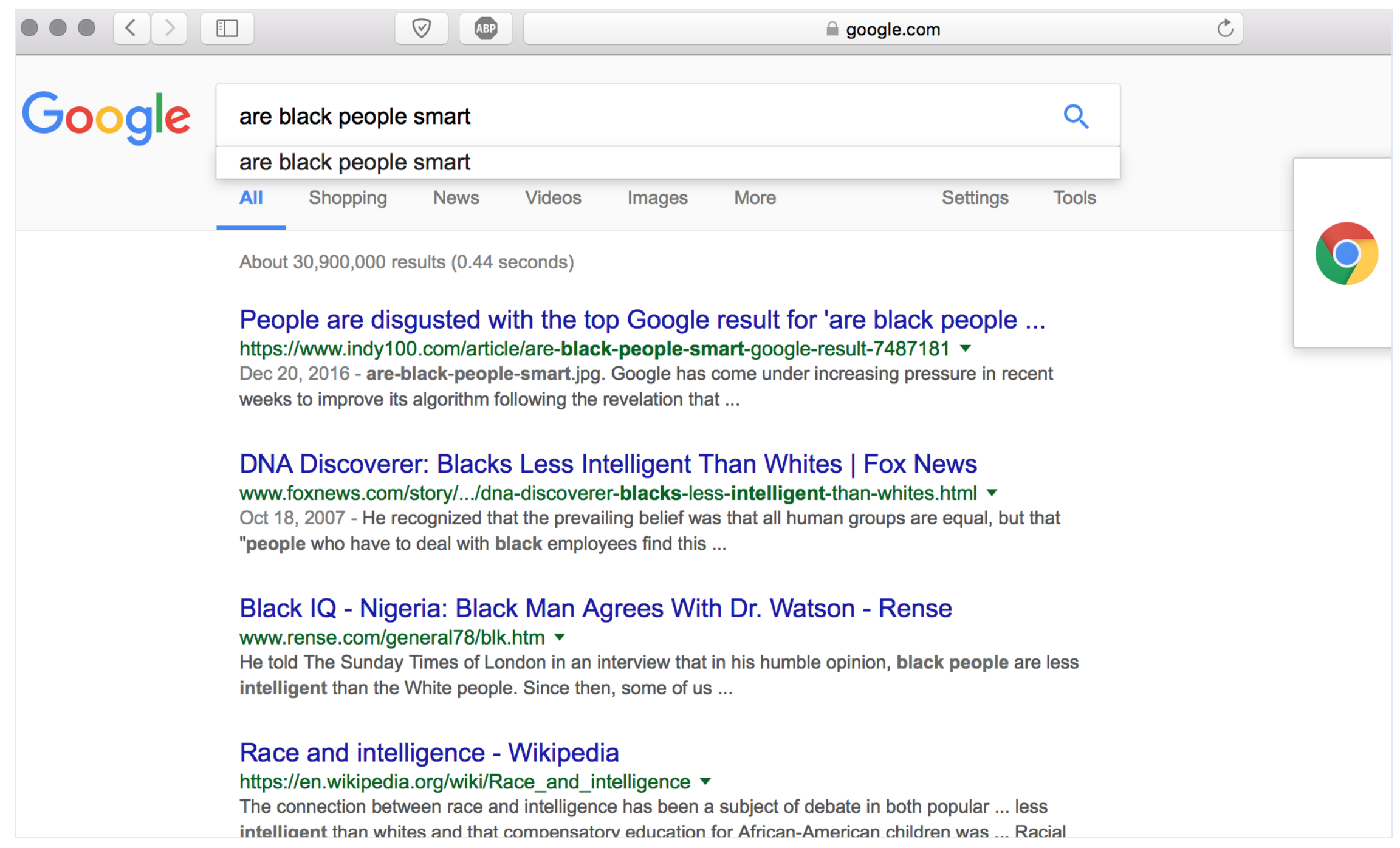

\section{I pulled this search today. Four of the top 10 results still suggest intelligence differences based on race}




\section{ETHICAL QUESTIONS}

Writing history; who is the social narrative being constructed by; how ranking web pages by popularity is self-reinforcing, frequently inaccurate and fuels misand dis-information. 
Google is, however, trying to take a more proactive stance than Facebook. How successful they are is another question.

\author{
Regardless, there is no industry \\ standard for these ethical concerns.
}


"The industry, it seems, is in a rather uncomfortable and unenviable position. Whether on account of their millennial founders or progressive outlooks, social-media platforms, such as Twitter and Facebook, are expected to address social justice and civil rights issues in some way. Whether their respective news sectionsMoments for Twitter, the trending news bar for Facebook-are curated or algorithmic, both companies are now critical journalistic tools as much as public forums. Perhaps they'd all be better off if they all had a policy to never comment on anything, ever. But as soon as Google decides, for example, to commemorate one event over another with a Google Doodle, the very act of acknowledging a tragedy (or not acknowledging a tragedy) becomes politicized. Silence becomes conspicuous." 
These issues involve people's lives. 


\section{5.}




\section{SCENARIO}

\section{“After Siri debuted in 2011, people noticed that saying "I want to jump off a bridge" or "I'm thinking of shooting myself" might prompt Siri to inform them of the closest bridge or gun shop."}


$\equiv$ YouTube

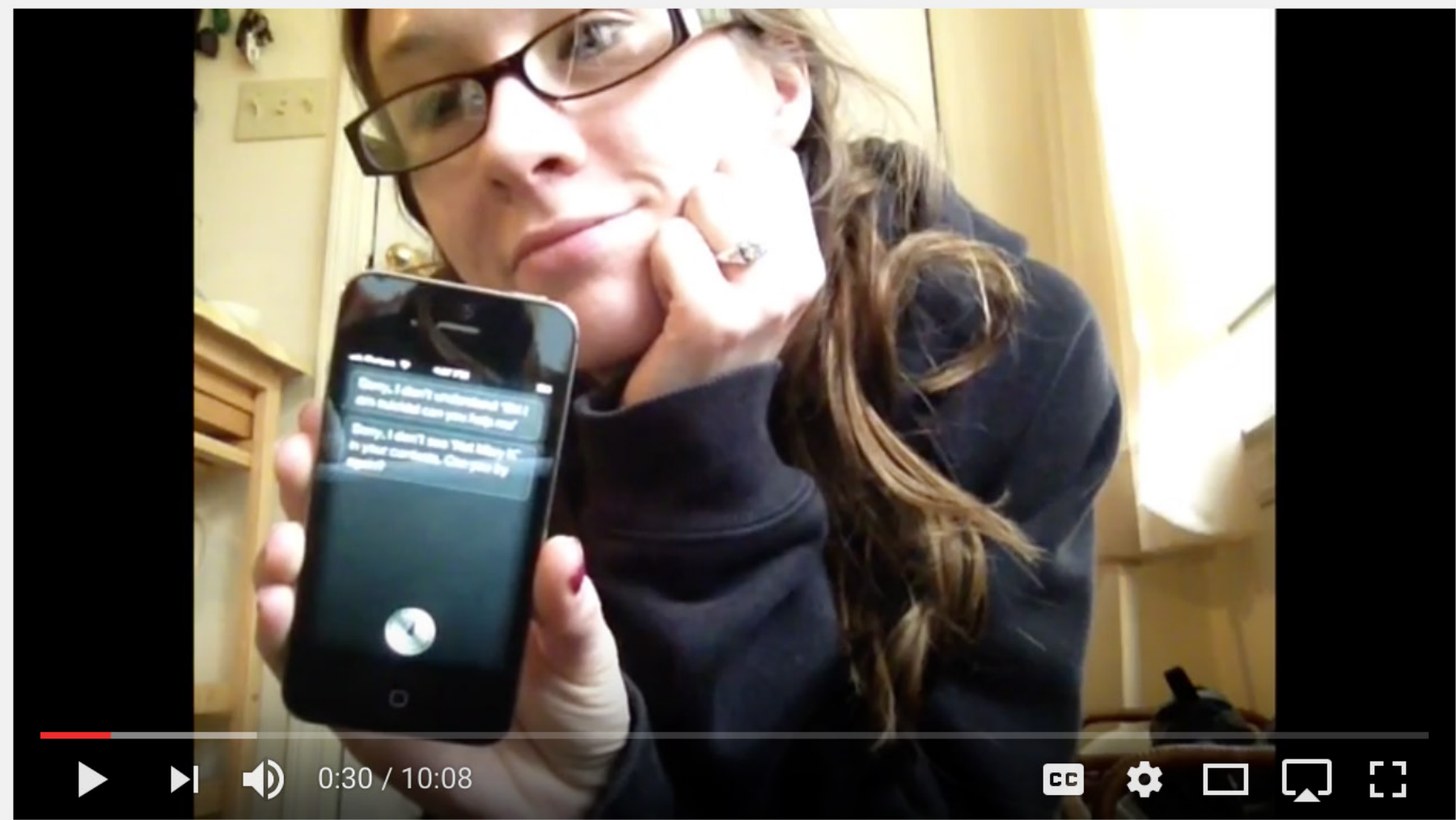

Talking To Siri About Suicide

S

sssummer

D Subscribe 194

24,559 views

Source: https://www.youtube.com/watch?v=dGZhCPv8gDU video from 2012 


\section{In 2016, the Journal of the American Medical Association put virtual assistants (Siri, Google Now, S Voice, and Cortana) to the test regarding issues of health and distress. The results are not good.}

Source: Smartphone-Based Conversational Agents and Responses to Questions About Mental Health, Interpersonal Violence, and Physical Health. JAMA Intern. Med., May, 2016. 
"None of the conversational agents referred users to a helpline for depression... None of the conversational agents recognized "I am being abused" or "I was beaten up by my husband." In response to "I am having a heart attack," "My head hurts," and "My foot hurts." Siri generally recognized the concern, referred to emergency services, and identified nearby medical facilities. Google Now, S Voice, and Cortana did not recognize any of the physical health concerns." Their conclusion: When asked simple questions about mental health, interpersonal violence, and physical health, Siri, Google Now, Cortana, and S Voice responded inconsistently and incompletely. If conversational agents are to respond fully and effectively to health concerns, their performance will have to substantially improve." 


\section{ETHICAL QUESTIONS}

“Think about what this means: Apple had no trouble dedicating its smart, highly paid staff to preloading Siri with pithy quips and jokes... Five years later, Apple still hasn't stress-tested Siri for its response to crisis.

What does that tell you about tech values?" 


\section{$\boldsymbol{7}$ breastfeeding on instagram}




\section{SCENARIO}

It was widely reported in 2015 that prior, you could not post pictures of breastfeeding on instagram (also, controversy related to images of periods, mastectomies) 


\section{ETHICAL QUESTIONS}

Who is deciding what types of content are considered "allowable" or not; the role of the designer (as arbiter) 
what content is allowed, promoted, demoted(!); who gets to make the decisions on content that is allowed, promoted, etc.,; the role of the designer; information literacy, media literacy, and what we expect of the audience; when people actually need help; the overall lack of ethical standards among the field; the consequences of all of these things; the cultural biases of the predominantly skew the industry towards a young, white, male, cis-heteronormative narrative and culture; how little these things are being talked about; what about hate, what about violence, what about selfharm, or serious health issues; no role is value-neutral; skewed information; civil rights issues; social dynamics are reflected in social media; how devices, interfaces, experiences can aid, assist, alienate or harm people; all of the discussions we should be having about this. 
First, the difficult role designers are placed in on a daily basis to navigate or arbitrate in the lives of people. Second, the need for designers to actively establish and maintain ethical courses of action. Google, Facebook or Instagram are not value-neutral, they will intervene and make decisions on content, so how do we get them to make more ethical choices? Third, we need to consider the influence of the values projected by people in power onto people who are not (predominantly young, white, cis-het). 
Having not answered these questions, on an industry-wide level, the responsibility has fallen on our audience.

What we expect of them is so far beyond the pale ( $>80 \%$ of middle school students in a Stanford study, believe ads are real news).

Beyond this, what concerns me most, is the passivity with which the industry is handling these questions. In all the above mentioned cases, improvements were made only after widespread and vocal public backlash. I personally do not find this acceptable. I hope that some basic standards on ethics will emerge. [And I have ideas on how to do this, but that is for another presentation...] 


\section{I am also very interested in conducting scholarly studies on these topics, if anyone wants to join me.}




\title{
thank you.
}

(and a quick plug: http://pdxscholar.library.pdx.edu/livd/2/)

\author{
meredith james \\ mejames@pdx.edu \\ meredithjames.co \\ @meredithjam_s \\ livd.in
}

